\title{
Calcr, a brain-specific imprinted mouse calcitonin receptor gene in the imprinted cluster of the proximal region of chromosome 6
}

Received: 18 October 2002/ Accepted: 23 January 2003/Published online: 12 March 2003

(C) The Japan Society of Human Genetics and Springer-Verlag 2003

\begin{abstract}
Expressed sequence tags (ESTs) in the human chromosome 7q21-q31 region were recently used to screen for allelic expression bias in monochromosomal hybrids retaining a paternal or maternal human chromosome 7. Six candidate imprinted genes were identified. In this study, we investigated parent-of-originspecific expression profiles of their mouse homologues in the proximal region of chromosome 6. An imprinting analysis, using $\mathrm{F} 1$ mice from reciprocal crosses between the B6 and JF strains, demonstrated that the mouse calcitonin receptor gene (Calcr) was expressed preferentially from the maternal allele in brain, whereas no allelic bias was detected in other tissues. Our results indicate that $\mathrm{Calcr}$ is imprinted in a tissue-specific manner, with a predominant expression from the maternal allele in the brain.
\end{abstract}

Keywords Genomic imprinting · Parent-of-originspecific expression - Tissue-specific $\cdot$ Calcitonin receptor $\cdot$ Imprinted cluster

\section{Introduction}

Genomic imprinting is an epigenetic mechanism in mammals, which leads to non-equivalent expression from the maternal and paternal genomes. Approximately 40 imprinted genes have been identified that may play an important role in the early development, and disrupted imprinting manifests as disorders involving developmental abnormalities, congenital diseases,

H. Hoshiya $\cdot$ M. Meguro $\cdot$ A. Kashiwagi

C. Okita $\cdot$ M. Oshimura $(\bowtie)$

Division of Molecular and Cell Genetics,

Department of Molecular and Cellular Biology,

School of Life Sciences, Faculty of Medicine,

Tottori University, 86 Nishimachi, Yonago 683-8503, Japan

E-mail: oshimura@grape.med.tottori-u.ac.jp

Tel.: + 81-859-34-8261

Fax: $+81-859-34-8134$ malignant tumors and abnormal behavior (Tilghman 1999; Reik and Walter 2001). Most imprinted genes are clustered in chromosomal domains, which is utilized for systematic screening of novel imprinted genes. To develop an in vitro assay system for the investigation of imprinted loci in humans, we have previously established the human monochromosomal hybrids that contain a human chromosome of defined parental origin, via microcell-mediated chromosome transfer (Kugoh et al. 1999; Inoue et al. 2001). This in vitro assay system led to the identification of novel imprinted genes by screening for ESTs that show parent-of-origin-specific expression profiles within the well-documented imprinting clusters (Mitsuya et al. 1999; Meguro et al. 2001). Using hybrids with a paternal or maternal human chromosome 7, we have recently determined the allelic expression profiles of 76 ESTs mapped to human chromosome 7q21-q31. Seven genes/transcripts including PEG10 that was previously reported to be imprinted, were identified as candidate imprinted genes and one candidate, $D L X 5$, was confirmed to be expressed preferentially from the maternal allele in normal human lymphoblasts (Okita et al. 2003). In this study, we investigated the allelic expression profiles of the mouse genes homologous to the human transcripts that showed parent-of-origin-specific expression in monochromosomal hybrids, using normal tissues from the reciprocal F1 crosses of B6 and JF mice. We demonstrated here that the mouse calcitonin receptor gene (Calcr) was imprinted specifically in the brain, with predominant expression of the maternal allele.

\section{Materials and methods}

Mouse homologues of the selected human genes were identified using the UniGene and BLAST programs on the NCBI server (http://www.ncbi.nlm.nih.gov/). The mouse strains C57BL/6 J (B6) and JF1 (JF) were used to screen for nucleotide polymorphisms. Genomic DNA was amplified by PCR using primers which were generated to sequence in the $5^{\prime}$ or $3^{\prime}$ untranslated regions of these genes. PCR products were purified using a QIAquick column (Qiagen, Chatsworth, CA) and directly sequenced from both 
directions using a Thermo Sequenase Cycle Sequencing Kit (Amersham Biosciences, Piscataway, NJ) on a LI-COR DNA sequencer 4200 (LI-COR, Lincoln, NE). Total RNA was extracted from adult and day-15.5 embryo tissues of $(\mathrm{B} 6 \times \mathrm{JF}) \mathrm{F} 1$ and $(\mathrm{JF} \times \mathrm{B} 6) \mathrm{F} 1$ using the single-step acid guanidinium isothiocyanate procedure. RNA was treated with RNase-free DNase I (Wako Nippon Gene, Tokyo, Japan) before the reverse transcription reaction. First strand cDNA synthesis was carried out with an oligo $(\mathrm{dT})_{15}$ primer (Roche Diagnostics Corporation, Indianapolis, IN) and with or without M-MLV reverse transcriptase (Invitrogen Corp, Carlsbad, CA). For expression analysis of Calcr, the following oligonucleotides were used: 5'-AGCAACTGTGGACCTTGGAT-3' and 5'-GCGTTTCCCACAATTTAGGT-3'. The cDNA template was amplified by PCR with Taq polymerase (Roche Molecular Systems, Branchburg, NJ). PCR products were digested with MnlI (New England Biolabs, Beverly, MA).

\section{Results and discussion}

Six human genes/transcripts were identified as candidate imprinted genes by screening for ESTs which were located on the human chromosome 7q21-q31 region using mouse A9 hybrids retaining a single paternal or maternal human chromosome 7. Mouse homologues were identified for four of these candidates, by searching the GeneBank database. All mapped to proximal mouse chromosome 6 , which is the syntenic region to the human chromosome 7q21-q31 imprinted cluster (Fig. 1). To investigate their allelic expression profiles, we sought to identify transcribed sequence polymorphisms between B6 and JF mice. Direct sequencing of PCR products that were amplified from the $5^{\prime}$ or $3^{\prime}$ untranslated regions (UTR) of these genes identified a single nucleotide polymorphism (SNP) in the $3^{\prime}$ UTR of the Calcr gene. SNPs were not identified in the remaining three candidates. The SNP of Calcr produced an $M n l I$ restriction site on the JF allele but not on the B6 allele. Calcr expression was detected by RT-PCR at high levels in adult brain, lung and kidney and a lower level in muscle, and was also detected in day-15.5 whole embryo and brain tissues (Fig. 2). We performed the restriction analysis on PCR products from these tissues. In the $(\mathrm{JF} \times \mathrm{B} 6) \mathrm{F} 1$ adult mouse, Calcr transcripts were derived preferentially from the maternal JF allele in the brain, whereas Calcr showed no allelic bias in other tissues (Fig. 3). Likewise, predominantly maternal expression was observed only in the adult brain tissue from $(\mathrm{B} 6 \times \mathrm{JF}) \mathrm{F} 1$ mice (Fig. 3). This maternal expression of Calcr was confirmed also in day-15.5 embryo brain tissue (Fig. 3). Hence, we conclude that mouse Calcr is imprinted and expressed preferentially from the maternal allele only in the brain and expressed biallelically in other tissues.

Expression of human $C A L C R$ was detected in A9 hybrids with a maternal human chromosome 7 (Okita et al. 2003). Despite the repetition of RT-PCR, mouse Calcr expression was not detected in adult fibroblasts. In the previous study, $P E G 3$ was paternally expressed in human brain, but not detected in human fibroblasts (Maegawa et al. 2001). However, expression of PEG3 was detected by RT-PCR in mouse A9 hybrids containing a paternal allele

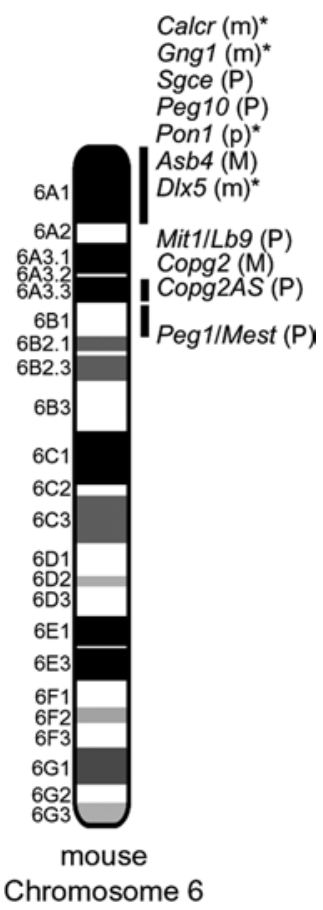

Fig. 1 Imprinted genes on mouse chromosome 6. Paternally (P) or maternally (M) expressed genes were previously identified in mouse. Asterisks show four mouse homologues of the differentially expressed transcripts identified as candidate imprinted genes by screening of human monochromosomal hybrids. The candidate genes were expressed only from a maternal (m) or a paternal (p) chromosome in A9 hybrids

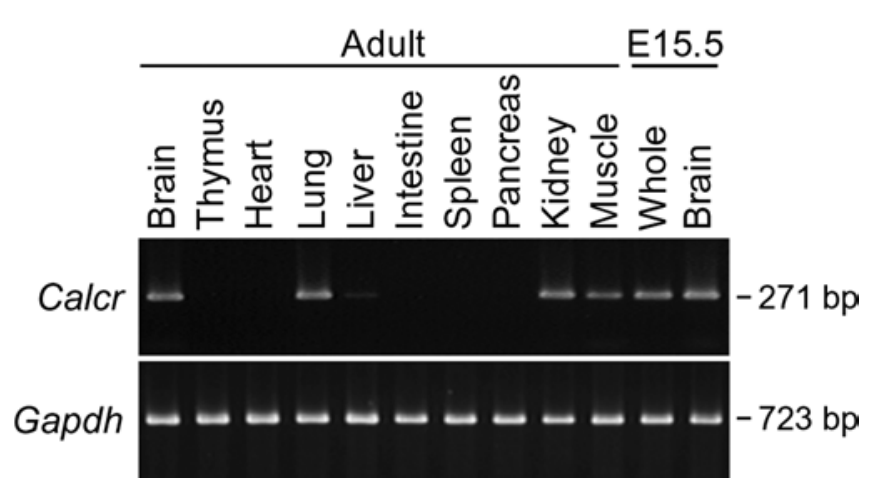

Fig. 2 Tissue-specific expression of Calcr. Total RNA from adult mouse brain, thymus, heart, lung, liver, intestine, spleen, pancreas, kidney, and muscle and day-15.5 (E15.5) whole embryo and brain were analyzed by RT-PCR using Calcr specific primers. Glyceraldehyde-3-phosphate dehydrogenase (Gapdh) was used as a control. The PCR cycle numbers used were 35 and 32 for Calcr and Gapdh, respectively. The expected PCR product size is shown on the right of each panel

of human chromosome 19 derived from fibroblasts. $D L X 5$ was maternally expressed in mouse A9 hybrids, but not detected in human fibroblasts (Okita et al. 2003). The reason of this phenomenon is unclear. However, it is possible that the expression was enhanced in mouse A9 cells, uncovering the allelic bias. Thus, mouse A9 cells are 


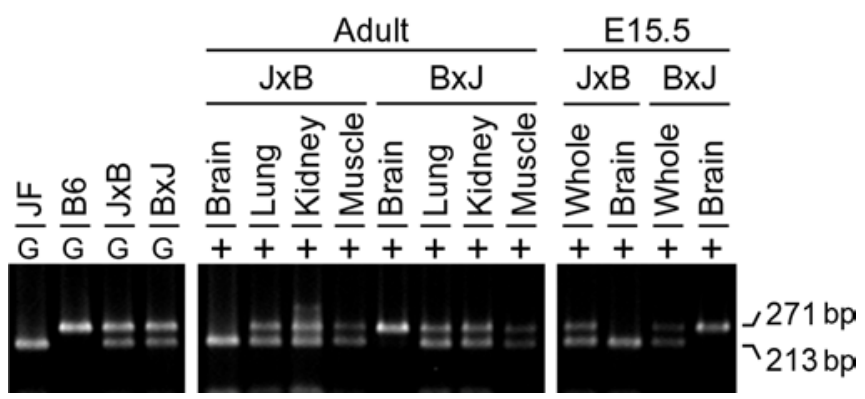

Fig. 3 Allele-specific expression analysis of Calcr using the reciprocal crosses $(\mathrm{JF} \times \mathrm{B} 6) \mathrm{F} 1$ and $(\mathrm{B} 6 \times \mathrm{JF}) \mathrm{F} 1$. PCR products were digested with $M n l \mathrm{I}$ and separated on a $2 \%$ agarose gel. The JF allele produced two fragments of 213-bp and 58-bp, whereas the B6 allele produced the undigested 271-bp fragment. The 58-bp fragment was not shown in the photograph. The maternally derived allele of Calcr was expressed in the adult and E15.5 brain tissues. $\mathrm{J} \times \mathrm{B} ;(\mathrm{JF} \times \mathrm{B} 6) \mathrm{F} 1, \mathrm{~B} \times \mathrm{J} ;(\mathrm{B} 6 \times \mathrm{JF}) \mathrm{F} 1$. G; genomic DNA, + ; cDNA

useful for detecting novel imprinting genes even if they are tissue-specific.

The proximal region of mouse chromosome 6 that has a syntenic homology to the human chromosome 7q21-q31 region was presented as a new imprinted cluster. Four imprinted genes have previously been isolated from this region in human and mouse (Piras et al. 2000; Ono et al. 2001; Mizuno et al. 2002; Okita et al. 2003). Calcr was localized close to these genes, indicating that it was a new member of this imprinted cluster (Fig. 1). Calcr was classified as a member of the seven transmembrane domain $\mathrm{G}$ protein-coupled receptor superfamily. Calcitonin, a 32-amino-acid peptide hormone, binds to Calcr and regulates $\mathrm{Ca}^{2+}$ concentrations by inhibiting osteoclastic bone reabsorption and increasing $\mathrm{Ca}^{2+}$ excretion from the kidney (Pondel 2000). Calcr has been demonstrated in a variety of tissues not directly involved in the regulation of $\mathrm{Ca}^{2+}$ homeostasis. Especially, expression of Calcr has been observed in the brain, suggesting that it has distinct functions also in the central nervous system (CNS) (Fischer et al. 1981). In the CNS, calcitonin is thought to enhance the secretion of anterior pituitary hormones and inhibit appetite and gastric acid secretion (Pondel 2000). Recently, Nakamoto et al. reported that calcitonin acts to produce antinociceptive effects in mice (Nakamoto et al. 1999). They also demonstrated that Calcr was expressed in various brain regions that are known to play important roles in pain modulation, and was expressed intensely in serotonergic pathways during the analgesic effects of calcitonin (Nakamoto et al. 2000). Interestingly, biochemical abnormalities in the serotonin system have been associated with autistic disorders (Andres 2002). The long arm of human chromosome 7 is the locus that is linked to autism (Lamb et al. 2000). In addition, an autistic disorder family with inversion in the chromosome 7 candidate region showed a parent-of-origin-specific effect (Ashley-Koch et al. 1999). Therefore, it is possible that the brain-specific imprinting of Calcr may be involved in pain modulation or in etiologies of autism. The Calcr cDNA cloning studies have revealed the existence of multiple isoforms derived from alternative splicing of transcripts (Yamin et al. 1994; Anusaksathien et al. 2001). These isoforms are functionally distinct and are likely to be tissue- or species-specific. The tissue-specific imprinted expression of Calcr may be regulated in an isoform-specific manner by utilization of an alternate promoter. The generation of targeted mutations in mice could enable the analysis of the role and mechanisms of the regulation of brainspecific imprinting of Calcr in the CNS.

Acknowledgements This study was supported by grants from the Ministry of Education, Culture, Sports, Science, and Technology of Japan.

\section{References}

Andres C (2002) Molecular genetics and animal models in autistic disorder. Brain Res Bull 57:109-119

Anusaksathien O, Laplace C, Li X, Ren Y, Peng L, Goldring SR, Galson DL (2001) Tissue-specific and ubiquitous promoters direct the expression of alternatively spliced transcripts from the calcitonin receptor gene. J Biol Chem 276:22663-22674

Ashley-Koch A, Wolpert CM, Menold MM, Zaeem L, Basu S, Donnelly SL, Ravan SA, Powell CM, Qumsiyeh MB, Aylsworth AS, Vance JM, Gilbert JR, Wright HH, Abramson RK, DeLong GR, Cuccaro ML, Pericak-Vance MA (1999) Genetic studies of autistic disorder and chromosome 7. Genomics 61:227-236

Fischer JA, Tobler PH, Kaufmann M, Born W, Henke H, Cooper PE, Sagar SM, Martin JB (1981) Calcitonin: regional distribution of the hormone and its binding sites in the human brain and pituitary. Proc Natl Acad Sci USA 78:7801-7805

Inoue J, Mitsuya K, Maegawa S, Kugoh H, Kadota M, Okamura D, Shinohara T, Nishihara S, Takehara S, Yamauchi K, Schulz TC, Oshimura M (2001) Construction of 700 human/mouse A9 monochromosomal hybrids and analysis of imprinted genes on human chromosome 6. J Hum Genet 46:137-145

Kugoh H, Mitsuya K, Meguro M, Shigenami K, Schulz TC, Oshimura M (1999) Mouse A9 cells containing single human chromosomes for analysis of genomic imprinting. DNA Res $6: 165-172$

Lamb JA, Moore J, Bailey A, Monaco AP (2000) Autism: recent molecular genetic advances. Hum Mol Genet 9:861-868

Maegawa S, Yoshioka H, Itaba N, Kubota N, Nishihara S, Shirayoshi Y, Nanba E, Oshimura M (2001) Epigenetic silencing of PEG3 gene expression in human glioma cell lines. Mol Carcinog 31:1-9

Meguro M, Mitsuya K, Nomura N, Kohda M, Kashiwagi A, Nishigaki R, Yoshioka H, Nakao M, Oishi M, Oshimura M (2001) Large-scale evaluation of imprinting status in the PraderWilli syndrome region: an imprinted direct repeat cluster resembling small nucleolar RNA genes. Hum Mol Genet 10:383394

Mizuno Y, Sotomaru Y, Katsuzawa Y, Kono T, Meguro M, Oshimura M, Kawai J, Tomaru Y, Kiyosawa H, Nikaido I, Amanuma H, Hayashizaki Y, Okazaki Y (2002) Asb4, Ata3, and Den are novel imprinted genes identified by highthroughput screening using RIKEN cDNA microarray. Biochem Biophys Res Commun 290:1499-1505

Mitsuya K, Meguro M, Lee MP, Katoh M, Schulz TC, Kugoh H, Yoshida MA, Niikawa N, Feinberg AP, Oshimura M (1999) LIT1, an imprinted antisense RNA in the human KvLQT1 locus identified by screening for differentially expressed transcripts using monochromosomal hybrids. Hum Mol Genet 8:1209-1217 
Nakamoto H, Soeda Y, Seki T, Watanabe T, Satoh M (1999) Possible involvement of descending serotonergic systems in antinociception by centrally administered elcatonin in mice. Biol Pharm Bull 22:691-697

Nakamoto H, Soeda Y, Takami S, Minami M, Satoh M (2000) Localization of calcitonin receptor mRNA in the mouse brain: coexistence with serotonin transporter mRNA. Brain Res Mol Brain Res 76:93-102

Okita C, Meguro M, Hoshiya H, Haruta M, Sakamoto Y, Oshimura M (2003) A new imprinted cluster on the human chromosome 7q21-q31, identified by human-mouse monochromosomal hybrids. Genomics, in press

Ono R, Kobayashi S, Wagatsuma H, Aisaka K, Kohda T, Kaneko-Ishino T, Ishino F (2001) A retrotransposon-derived gene, PEG10, is a novel imprinted gene located on human chromosome 7q21. Genomics 73:232-237

Piras G, El Kharroubi A, Kozlov S, Escalante-Alcalde D, Hernandez L, Copeland NG, Gilbert DJ, Jenkins NA, Stewart CL
(2000) Zac1 (Lot1), a potential tumor suppressor gene, and the gene for $\epsilon$-sarcoglycan are maternally imprinted genes: identification by a subtractive screen of novel uniparental fibroblast lines. Mol Cell Biol 20:3308-3315

Pondel M (2000) Calcitonin and calcitonin receptors: bone and beyond. Int J Exp Pathol 81:405-422

Reik W, Walter J (2001) Genomic imprinting: parental influence on the genome. Nat Rev Genet 2:21-32

Tilghman SM (1999) The sins of the fathers and mothers: genomic imprinting in mammalian development. Cell 96:185-193

Yamin M, Gorn AH, Flannery MR, Jenkins NA, Gilbert DJ, Copeland NG, Tapp DR, Krane SM, Goldring SR (1994) Cloning and characterization of a mouse brain calcitonin receptor complementary deoxyribonucleic acid and mapping of the calcitonin receptor gene. Endocrinology 135:26352643 